\title{
The Research of PCD Tool Sharpening Process Parameters Based On Uniform Design
}

\author{
Zhang zhengyi \\ College of Mechanical Engineering and Automation \\ Xihua University \\ Chengdu, $\mathrm{CHN}$ \\ email: zhangzhengyi.1989@163.com
}

Deng Zhiping

College of Mechanical Engineering and Automation

Xihua University

Chengdu, $\mathrm{CHN}$

email: zhipingdeng@mail.xhu.edu.cn

\author{
Jin Long \\ College of Mechanical Engineering and Automation \\ Xihua University \\ Chengdu, CHN \\ email: 13540701923@163.com
}

\author{
Long Jun \\ College of Mechanical Engineering and Automation \\ Xihua University \\ Chengdu,CHN \\ email: longjun_xh@163.com
}

\begin{abstract}
The grinding process parameters and grinding quality of PCD tool is an area still full of questions to be resolved.This paper bases on the uniform test method, process parameters of PCD tool sharpening are seen as the level factors, thus in different conditions of level factors have carried on actual grinding experiments for many times, getting a lot of grinding data; regression analysis this data and the establishment of regression mathematics model, obtaining the regression equation and the regression equation is for F-test, the reliability of the models is proved.
\end{abstract}

Keywords:uniform design;PCD cutting tool; regression analysis,;grinding

\section{INTRODUCTION}

With the emergence of difficult-to-machine materials, the traditional tool material is increasingly difficult to meet the needs of the processing. In recent years, due to the good physical and chemical properties of super-hard material polycrystalline diamond (PCD), which has been widely used in the tools, cutting speed is one order of magnitude higher than the carbide, the tool life has also greatly improved[1-3].Based on economic considerations, currently the most widely used PCD tool sharpening method is the PCD grinding wheel grinding PCD cutting tools. Because their hardness is close, making PCD cutting tool is more difficult compared to other materials,is not easy to get stable grinding quality[4-6]. The previous have done a lot of research about the PCD tool on the removal rate and wear ratio, and make great achievements, however, the grinding process parameters and grinding quality lacks of research.

This paper bases on the uniform design tools for PCD cutting process parameters, establishing the regression model, and $\mathrm{F}$ test to verify the reliability of the model[7-8],then what is can provide imitate and guidance for improve sharpening quality about the PCD grinding wheel grinding PCD cutting tools on the actual production.

\section{EXPERIMENT DESIGNS}

\section{A. Experimental design method}

This article chooses uniform experimental design method to design, and divide into the following steps: First according to the need to examine the objective function, determining test indicators. Second combining actual production experience and relevant professional knowledge select test factors. Third according to the test conditions and experience to select the range of experiment factors divide the test level. Fourth designing uniform design table, arranging factor and level. Last determine the experimental program for test[9].

B. Experimental design

1) Test method: uniform test method.

2) Test equipment: PCD/CBN special grinder, diamond grinding wheel, PCD blade.

3) Objective function: flank surface roughness, grinding depth, edge serrated degree and edge radius.

4) Test factors: grinding wheel granularity (qualitative), grinding wheel concentration, grinding speed, grinding pressure, swing frequency.

In the arrangement of the above test factors and test indicators, testing with qualitative factors should be used mixed-level test. Since there is no ready-made uniform design table for choosing, this paper uses uniform design software version 5.0 operation to randomly generate uniform design table U15 $(15 \times 5 \times 5 \times 3 \times 3)$, using to arrange experiments. In order to ensure the accuracy of the test data, 
test is arranged under the same test parameters of two blades, each blade tests two times, the average value of the four times' measurements is seen as the grinding depth.
Arranged test table is shown in table I, the corresponding test level of each factor is shown in table II.

TABLE I : U15 $(15 \times 5 \times 5 \times 3 \times 3)$ ARRANGEMENT OFUNIFORM EXPERIMENT

\begin{tabular}{|c|c|c|c|c|}
\hline Speed (r/min) & $\begin{array}{c}\text { Pressure } \\
(\mathbf{M P})\end{array}$ & Frequency (times/min) & Concentration (\%) & Wheel granularity \\
\hline 1200 & 0.48 & 20 & 125 & W10 \\
\hline 2200 & 0.12 & 40 & 100 & W10 \\
\hline 1600 & 0.48 & 50 & 75 & W5 \\
\hline 1800 & 0.36 & 30 & 100 & W5 \\
\hline 2400 & 0.24 & 30 & 75 & W20 \\
\hline 2800 & 0.24 & 50 & 125 & W20 \\
\hline 3000 & 0.12 & 20 & 75 & W5 \\
\hline 2600 & 0.60 & 60 & 100 & W10 \\
\hline 2000 & 0.60 & 30 & 125 & W10 \\
\hline 3600 & 0.36 & 60 & 75 & W20 \\
\hline 1400 & 0.12 & 60 & 100 & W5 \\
\hline 3200 & 0.36 & 50 & 125 & W20 \\
\hline 3400 & 0.60 & 40 & 75 & W5 \\
\hline 3800 & 0.24 & 40 & 125 & W20 \\
\hline 4000 & 0.48 & 20 & 100 & \\
\hline
\end{tabular}

TABLE II : TEST VARIOUS FACTORS ATTAINMENT TABLE

\begin{tabular}{|c|c|c|c|c|}
\hline Speed (r/min) & $\begin{array}{c}\text { Pressure } \\
(\mathbf{M P})\end{array}$ & Frequency (times/min) & Wheel granularity & Concentration (\%) \\
\hline 1200 & 0.12 & 20 & W5 & 75 \\
\hline 1400 & 0.24 & 30 & W10 & 100 \\
\hline 1600 & 0.36 & 40 & W20 & 125 \\
\hline 1800 & 0.48 & 50 & & \\
\hline 2000 & 0.60 & 60 & & \\
\hline 2200 & & & & \\
\hline 2400 & & & & \\
\hline 2600 & & & & \\
\hline 2800 & & & & \\
\hline 3000 & & & & \\
\hline 3200 & & & & \\
\hline 3400 & & & & \\
\hline 3600 & & & & \\
\hline 3800 & & & & \\
\hline 4000 & & & & \\
\hline
\end{tabular}

\section{TESTS RESULTS}

In the acquisition process of test results, grinding depth measures by the micrometer, before and after the test, measuring the width of the blade, the difference between the two measurements is the grinding depth, the same set of data tests two times for "A" blade, taking average value of the two times' measurement as $\mathrm{m}$, similarly measuring average value of "B" blade's grinding depth takes it as n, entering the average value of $\mathrm{m}$ and $\mathrm{n}$ in the table. Measuring the edge serrated degree and the edge radius 
need special equipment, it adopts MikroCAD system as testing equipment which is imported from the German GFM company, it can measure the edge of blade quickly, including the edge serrated degree, edge radius, etc. Since the measurement of surface roughness is more difficult after PCD tool grinding, the surface roughness measuring equipment of this experiment test which measures the flank blade is called SURFCOM 480 type, which is imported

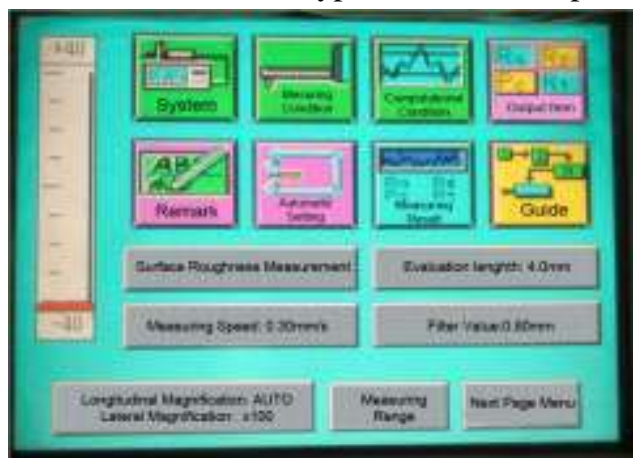

Figure 1. Sets measuring parameter from Japan. Putting the blade on workbench, mobilizing the position of the probe, and finally makes the probe contact with the blade flank, according to the need to set length which is measured, the test selects $4 \mathrm{~mm}$, measurement of speed can also be set, as shown in figure 1, clicking on the screen of the start measuring button, it can determine the surface roughness as shown in figure 2 , testing two periods of each blade, taking the average recorded.

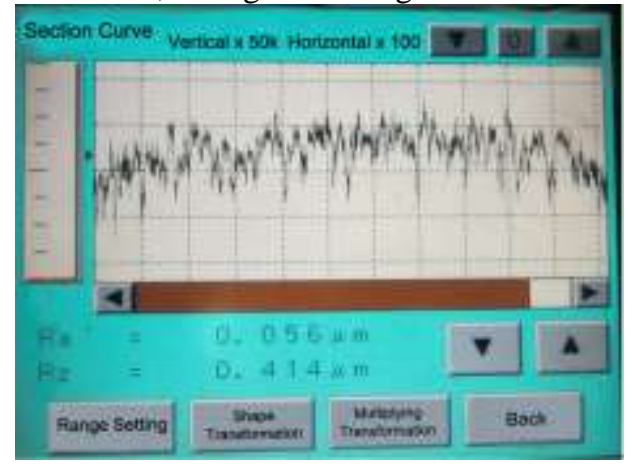

Figure 2. Surface roughness $\mathrm{Ra} 、 \mathrm{Rz}$

such as shown in table III

TABLEIII: EXPERIMENTAL RESULTS

\begin{tabular}{|c|c|c|c|c|}
\hline Speed (r/min) & Pressure (MP) & $\begin{array}{c}\text { Frequency } \\
\text { (time/min) }\end{array}$ & Concentration (\%) & $\begin{array}{c}\text { Serrated } \\
\text { degrees } \\
(\mu m)\end{array}$ \\
\hline 1200 & 0.48 & 20 & 125 & 0.9 \\
\hline 2200 & 0.12 & 40 & 100 & 0.85 \\
\hline 1600 & 0.48 & 50 & 75 & 0.85 \\
\hline 1800 & 0.36 & 30 & 100 & 0.8 \\
\hline 2400 & 0.24 & 30 & 75 & 1.0 \\
\hline 2800 & 0.24 & 50 & 125 & 0.8 \\
\hline 3000 & 0.12 & 20 & 15 & 0.8 \\
\hline 2600 & 0.60 & 60 & 125 & 0.9 \\
\hline 2000 & 0.60 & 30 & 75 & 0.85 \\
\hline 3600 & 0.36 & 60 & 100 & 0.8 \\
\hline 1400 & 0.12 & 60 & 125 & 1.0 \\
\hline 3200 & 0.36 & 50 & 75 & 0.9 \\
\hline 3400 & 0.60 & 40 & 125 & 0.85 \\
\hline 3800 & 0.24 & 40 & 100 & \\
\hline 4000 & 0.48 & 20 & & 0.8 \\
\hline
\end{tabular}

\section{THE TEST DATA REGRESSION ANALYSIS} AND INSPET

In order to establish the regression equation, the independent and dependent variables must be parameterized, qualitative factors " $\mathrm{A}$ " has three states (and level), namely $\mathrm{A} 1=\mathrm{W} 5=(1,0), \mathrm{A} 2=\mathrm{W} 10=(0,1), \mathrm{A} 3=\mathrm{W} 20=(0,0)$. So put the qualitative factors $A$ into three virtual variables. Obviously, only two of the three pseudo variables are linearly independent, $\mathrm{A} 1$ and $\mathrm{A} 2$.

In order to facilitate the expression, during the analysis of the process we parameter all factors and the objective function, set:X1=grinding speed $(\mathrm{r} / \mathrm{min}), \quad \mathrm{X} 2=$ grinding pressure (MP), X3=swing frequency (time $/ \mathrm{min}), \mathrm{X} 4=$ concentration $(\%), \mathrm{Y} 1=$ edge serrated degrees (um), $\mathrm{Y} 2=$ grinding depth (mm), Y3=edge radius (um), Y4=flank Ra (um), Y5=flank Rz (um). 
The regression analysis uses the uniform design results of regression analysis[10]: software. Inputting the data of the test results; getting the

TABLEIII: EXPERIMENTAL RESULTS

\begin{tabular}{|c|c|c|c|c|}
\hline $\begin{array}{c}\text { Grinding } \\
\text { Depth }(\mathbf{m m})\end{array}$ & $\begin{array}{c}\text { Edge Radius } \\
(\mu m)\end{array}$ & $\mathbf{R}_{\mathbf{a}}(\mu m)$ & $\mathbf{R}_{\mathbf{z}}(\mu m)$ & Wheel Granularity \\
\hline 0.068 & 8.0 & 0.058 & 0.52 & W10 \\
\hline 0.062 & 6.7 & 0.061 & 0.45 & W10 \\
\hline 0.030 & 5.2 & 0.056 & 0.40 & W5 \\
\hline 0.020 & 5.3 & 0.066 & 0.50 & W5 \\
\hline 0.082 & 10.0 & 0.070 & 0.51 & W20 \\
\hline 0.085 & 10.2 & 0.068 & 0.45 & W20 \\
\hline 0.042 & 5.2 & 0.053 & 0.41 & W10 \\
\hline 0.062 & 7.0 & 0.060 & 0.50 & W10 \\
\hline 0.060 & 7.5 & 0.067 & 0.48 & W10 \\
\hline 0.048 & 6.4 & 0.065 & 0.54 & W20 \\
\hline 0.028 & 9.5 & 0.066 & 0.49 & W20 \\
\hline 0.020 & 5.1 & 0.056 & 0.38 & W5 \\
\hline 0.075 & 13.0 & 0.066 & 0.55 & W20 \\
\hline 0.030 & 5.5 & 0.053 & 0.42 & \\
\hline 0.085 & 9.4 & 0.058 & 0.43 & \\
\hline
\end{tabular}

$\mathrm{Y}_{1}=0.9183807-0.0044520 *\left(\mathrm{X}_{4}-100\right)-0.0555099 * \mathrm{~A}_{1}+0.0000$ $621 *\left(\mathrm{X}_{1}-2600\right) \mathrm{A}_{1}-1.1719349 *\left(\mathrm{X}_{2}-0.36\right)\left(\mathrm{X}_{2}-0.36\right)-0.003837$ $9 *\left(\mathrm{X}_{2}-0.36\right)\left(\mathrm{X}_{4}-100\right)-0.0001298 *\left(\mathrm{X}_{3}-40\right)\left(\mathrm{X}_{3}-40\right)-0.0000160$ $*\left(\mathrm{X}_{3}-40\right)\left(\mathrm{X}_{4}-100\right)+0.0025689 *\left(\mathrm{X}_{3}-40\right) \mathrm{A}_{2}+0.0000244 *\left(\mathrm{X}_{4}-1\right.$ $00)\left(\mathrm{X}_{4}-100\right)+0.0025375^{*}$

$\left(\mathrm{X}_{4}-100\right) \mathrm{A}_{1}+0.0080886^{*}\left(\mathrm{X}_{4}-100\right) \mathrm{A}_{2}$

$\mathrm{Y}_{2}=0.0711081-0.0007586 *(\mathrm{X} 3-40)-0.0538010 * \mathrm{~A} 1+0.0117$ $319 * \mathrm{~A} 2-0.0000702 *\left(\mathrm{X}_{1}-2600\right)(\mathrm{X} 2-0.36)-0.0000007 *\left(\mathrm{X}_{1}-26\right.$ $00)(\mathrm{X} 3-40)-0.0000002 *\left(\mathrm{X}_{1}-2600\right)(\mathrm{X} 4-100)-0.2505032 *(\mathrm{X} 2$ $-0.36)(\mathrm{X} 2-0.36)+0.0019250 *(\mathrm{X} 2-0.36)(\mathrm{X} 3-40)-0.0031935 *$ $(\mathrm{X} 2-0.36)(\mathrm{X} 4-100)+0.0381155 *(\mathrm{X} 2-0.36) \mathrm{A} 1+0.0000409 *($ $\mathrm{X} 3-40)(\mathrm{X} 4-100)+0.0000129 *(\mathrm{X} 4-100)(\mathrm{X} 4-100)$

$\mathrm{Y}_{3}=10.2096945+3.6146872 *(\mathrm{X} 2-0.36)-5.2773689 * \mathrm{~A} 1-4.93$ $67953 * \mathrm{~A} 2+0.0000580 *(\mathrm{X} 1-2600)(\mathrm{X} 3-40)+27.1160919 *(\mathrm{X}$ $2-0.36)(\mathrm{X} 2-0.36)-0.0596402 *(\mathrm{X} 2-0.36)(\mathrm{X} 4-100)-3.252808$ $3 *(\mathrm{X} 2-0.36) \mathrm{A} 1-3.0608562 *(\mathrm{X} 2-0.36) \mathrm{A} 2-0.0007716 *(\mathrm{X} 3-4$ $0)(\mathrm{X} 4-100)+0.0161044 *(\mathrm{X} 4-100) \mathrm{A} 2$

$\mathrm{Y}_{4}=0.0721521-0.0000079 *(\mathrm{X} 1-2600)-0.0002987 *(\mathrm{X} 3-40)+$ $0.0001522 *(\mathrm{X} 4-100)-0.0100093 * \mathrm{~A} 1-0.0067795 * \mathrm{~A} 2-0.000$ $0002 *(\mathrm{X} 1-2600)(\mathrm{X} 4-100)+0.0000020 *(\mathrm{X} 1-2600) \mathrm{A} 1+0.000$ $0145 *(\mathrm{X} 1-2600) \mathrm{A} 2+0.0002039 *(\mathrm{X} 2-0.36)(\mathrm{X} 3-40)+0.0072$ $432 *(\mathrm{X} 2-0.36) \mathrm{A} 2-0.0000216 *(\mathrm{X} 3-40)(\mathrm{X} 3-40)+0.0001646 *$ (X3-40)A $1+0.0003261 *(\mathrm{X} 3-40) \mathrm{A} 2$
$\mathrm{Y}_{5}=0.4731518-0.0010623 *(\mathrm{X} 4-100)-0.0589159 * \mathrm{~A} 1+0.000$ $3856 *(\mathrm{X} 1-2600)(\mathrm{X} 2-0.36)+0.0000039 *(\mathrm{X} 1-2600)(\mathrm{X} 3-40)+$ $0.0000024 *(\mathrm{X} 1-2600)(\mathrm{X} 4-100)-0.0020044 *(\mathrm{X} 2-0.36)(\mathrm{X} 4-$ $100)+0.2543271 *(\mathrm{X} 2-0.36) \mathrm{A} 2-0.0000914 *(\mathrm{X} 3-40)(\mathrm{X} 4-100$ )$-0.0054242 *(\mathrm{X} 3-40) \mathrm{A} 1-0.0016899 *(\mathrm{X} 3-40) \mathrm{A} 2+0.000016$ $9 *(\mathrm{X} 4-100)(\mathrm{X} 4-100)$

Using analysis of variance technology tests the regression mode:

$$
F=\frac{S_{R} / p}{S_{e} /(n-p-1)} \sim F(p, n-p-1)
$$

$S_{R}$ :Regression sum of squares; $S_{e}$ :residual sum of squares; $P$ : degree of freedom of $S_{R} ; n-p-1$ :degree of freedom of $S_{e}$.

In a given significant level $\alpha$, if $F>F_{1-\alpha}(p, n-p-1)$ the regression model is credible.

For Y1 (serrated degrees), according to the uniform design software, getting the analysis of variance in table IV: 
TABLEIV : Y1 ANALYSIS OF VARIANCE TABLE

\begin{tabular}{|c|c|c|c|c|c|}
\hline Variance Source & Quadratic Sum & $\begin{array}{c}\text { Degree of } \\
\text { Freedom }\end{array}$ & Mean Square & F & P \\
\hline SR & 0.0538 & 11 & 0.0053 & 3400.5830 & 0.000007 \\
\hline SE & 0.0000 & 3 & 0.0000 & & \\
\hline ST & 0.0538 & 14 & & & \\
\hline
\end{tabular}

Given the significant level of 0.05 , you can check $\mathrm{F}_{0.05}(11,3)=8.763$, in table $4, \mathrm{~F}=3400.583>\mathrm{F}_{0.05}(11,3)$, so the regression equation of the $\mathrm{Y} 1$ regression effect is remarkable. According to the uniform design software analysis, $R^{2}=0.9999$, and the regression effect of regression equation of Y2, Y3, Y4 Y5 all are remarkable, the relationship between each independent variable is very close.

\section{CONCLUSIONS}

In this paper, firstly, according to the uniform designs the experiment, after many times grinding gets a large number of grinding actual data; Then using uniform design software analyzes this data and gets five independent nonlinear regression equations, which reflect the function relation between parameters and all the objectives of functions; Finally, making an analysis of variance of this regression equation ( $\mathrm{F}$ inspection), the results show that the regression effect of the five nonlinear regression equation is remarkable, the relationship between each independent variable is very close.Therefore, the research results can provide imitate and guidance for improve sharpening quality about the PCD grinding wheel grinding PCD cutting tools on the actual production.

\section{ACKNOWLEDGEMENT}

I would like to acknowledge the support from Postgraduate Innovation Fund of Xihua University (ycij2014053),the university key laboratory of Manufacturing and Automation of Sichuan Province at Xihua University and the support from the Professor Deng Zhiping for the second author.

\section{REFERENCE}

[1] Li Jie,and Wang Jinhui, “Review of grinding technology for diamond

Engineering,vol.46,Feb,2012,pp.3-6,doi:10.3969/j.issn.1000-7008.20 12.12.001

[2] Xin Taozhu,"Regression analysis and design of experiment," Beijing :normal university press, 2010.

[3] Su Huitao,"Processing method and technology of PCD cutting tool edge,"Superhard Material Engineering.vol.25,Aug.2013,pp.31-35,10.3969/j.issn.1673-1433.20 13.02.007.

[4] Wang Yongguo,Tu Guocai,and Liu Gang, "Key Processes for Manufacturing PCD Cutting Tools,"Too Engineering,vol.44,Jan.2010,pp.32-35,doi:10.3969/j.issn.1000-7008. 2010.01 .008

[5] Lu Xuejun,Li Jiangang,Xu Guojun,and Deng Fuming,"EDG Technology of PCD Tool with Internal Cutting Edges,"Electromachining and Mould,vol.2,Feb.2009,pp.58-61,doi:10.3969/j.issn.1009-279X.2009. 02.017 .

[6] Song Mancang,Zhang Jianlei,Yu Chao,Wang Minjie,and Liu Chong,"Experiment of WEDM Precision Machining for Polycrystalline Diamond Compact,"Optics and Precision Engineering,vol.6,Jun.2012,pp.1303-1310,doi:10.3788/OPE.2012200 6.1303 .

[7] Wang Shuangxi,Niu Shichao,Yu Jinbin,and Qin Lei,"Review of Grinding Technologies and Equipments for Diamond Cutting Tools,"Tool

Engineering,vol.44,Apr.2010,pp.3-7,doi:10.3969/j.issn.1000-7008.20 10.02.001.

[8] Xu Long,Li Man,Zhang Hongtao,and Dong Hai,"Study on Factors Influencing Grinding Quality of PCD Tools,"Diamond and Abrasives

Engineering,vol.2,Apr.2009,pp.44-49,doi:10.3969/j.issn.1006-852X. 2009.02.011.

[9] Deng Fuming,and Lu Xuejun,"Current Status,Problem and Prospects of High Speed Cutting Technology of Superhard Tools in China,"vol,27,Aug.2010,pp.242-246,doi:10.3969/j.issn.1003-7292.2 010.04.010.

[10] Yunyan Li, and Chuangrong Hu:Experimental design and data processing,Bei Jing: Chemical industry press, 2005. 